\title{
Influence of active packaging on quality attributes of dried wild pomegranate (Punica granatum L.) arils during storage
}

\author{
A. Sharma* and N. S. Thakur \\ Forestry, Nauni, Solan-173230 (Himachal Pradesh), INDIA. \\ *Corresponding author. E-mail: anshufst1989@gmail.com \\ Received: July 17, 2015; Revised received: December 25, 2015; Accepted: March 12, 2016
}

Department of Food Science and Technology (FST), Dr. Yashwant Singh Parmar University of Horticulture and

\begin{abstract}
Wild pomegranate (Punica granatum L.) is the only wild fruit of foothills of Himalaya which has got commercial importance in North India because of the high acidic nature of its arils. The objective of this investigation was to evaluate best packaging material for storage of mechanical cabinet dried wild pomegranate arils. The freshly extracted arils were pre-treated to check the browning and dried in mechanical cabinet drier at $60 \pm 2{ }^{\circ} \mathrm{C}$. Dried arils packed in different packaging material with or without moisture absorbers (salt or sugar sachet) were stored under ambient conditions $\left(18\right.$ to $28^{\circ} \mathrm{C}$ ) for 6 months. Although the slight changes in quality attributes of dried arils during storage were observed but the arils packed in Aluminium Laminated Pouch (ALP) containing salt (humectant) showed minimum increase in moisture (8.82 \%), non enzymatic browning (0.05 OD), hydroxy methyl furfural (2.85 $\mathrm{ppm})$, furfurals $(20.11 \mathrm{ppb})$ and retained highest amount of titratable acidity $(10.92 \%)$, total sugars $(24.20 \%)$, ascorbic acid $(11.75 \mathrm{mg} / 100 \mathrm{~g})$, anthocyanins $(30.81 \mathrm{mg} / 100 \mathrm{~g})$ and phenols $(112.38 \mathrm{mg} / 100 \mathrm{~g})$ among all packaging material. So, ALP can be used as a packaging material for the packaging of dried arils (anardana, Indian spice) on commercial scale. Putting of moisture absorber along with the arils inside the pouch as an active packaging system will be an additional advantage to retain the quality of anardana during storage.
\end{abstract}

Keywords: Active packaging, Anardana, Drying mode, Storage, Wild pomegranate

\section{INTRODUCTION}

Wild pomegranate (Punica granatum L.) belongs to family Punicaceae which resembles with cultivated pomegranate for various morphological characters (Bakshi et al., 2013). Wild pomegranate is widely distributed in drier and sub marginal land of mid hill region of outer Himalaya at an elevation of 900 to $1800 \mathrm{~m}$ above mean sea level. In India, it is widely distributed in three states viz., Himachal Pradesh (HP), Jammu and Kashmir and Uttarakhand. Limited fresh consumption and export market of fresh wild pomegranate fruit is due to its high acidity, difficult consumption, appearance disorders like dark color or skin cracks. However, the conventional utilization of this fruit lies in its dried arils which constitute the product 'anardana' (Pruthi and Saxena, 2005). The dried arils are acidic and help in improving mouth feel and digestion (Singh and Kingsley, 2008). High acidic nature of this fruit also makes it a very good souring agent in Indian chutneys, curries and other culinary preparations in dried form (Mahajan et al., 2004; Parashar et al., 2009). The dried wild pomegranate arils are also used in number of ayurvedic formulations for the cure of bronchitis, inflammations, dysentery, stomach ache, dyspepsia, hymenoletidosis and cardiac diseases (Jalikop et al., 2002). Fruit drying can play a vital role to improve economy, import export market and employment especially for women and farmers of rural areas in developing countries (FAO, 2000).

The economy of many farmers is dependent upon the returns from this fruit, however, proper techniques are not being followed for its drying and storage. During storage, moisture absorption has been found as a main reason for deterioration of the quality of arils in terms of colour, flavour, texture and chemical composition. In the view of the increasing demand of quality food products in past years (Thakur et al., 2010; Sharma et al., 2013), some efforts have been made to develop and preserve better quality anardana from wild pomegranate. But, improved scientific effects have not been made to screen out the proper packaging material for its longer shelf life as well as for efficient marketing. Most of the packaging materials are permeable to moisture to some extent, application of the concept of active packaging has a sustained influence on packaging properties and can balance moisture by using more hygroscopic moisture absorbers in the packed food (Lopez-Rubio et al., 2004). Thus, present research has been made in this direction to get better quality anardana, Indian spice after marketing and storage.

\section{MATERIALS AND METHODS}

Wild pomegranate fruits harvested at optimum maturity 
were procured from district Mandi of HP and brought to the laboratory for conducting the studies. Fruits after thorough washing in water were used for aril extraction and various physico-chemical analysis. Extracted arils were pretreated as suggested by Thakur et al. (2010). The pretreated arils were then dried in mechanical cabinet drier (at a constant temperature of $60 \pm 2{ }^{\circ} \mathrm{C}$ ), till they attain a constant weight. The cabinet dried arils of $100 \mathrm{~g}$ each were packed in three different packaging material viz., Aluminium Laminated Pouch (ALP) of 99.8 gsm thickness, Polyethylene Pouch (PEP) of 93.9 gsm thickness and Thermofoam Tray (TT) wrapped with shrinkable polypropylene transparent sheet. Small cloth sachets of common salt $(5 \mathrm{~g})$ and sugar $(5 \mathrm{~g})$ were also put along with dried arils in respective packaging material to prepare active system of packaging as per the details given in Table 1. These packed arils were stored in ambient temperature (18 to $28{ }^{\circ} \mathrm{C}$ ) upto a period of six months for storage studies. The observations for different quality characteristics were recorded at 0,3 and 6 months interval of storage. For the estimation of various physico-chemical characteristics of fresh as well as dried arils, standardized methods and instruments were used. Vernier calliper was used to measure the length and diameter of randomly selected fruits and the average fruit size was expressed in millimeter. A top pan balance was used to weigh fruits. The colour of randomly selected fruits and fresh arils was observed visually. The arils of fruits were counted individually and average number of arils per fruit was calculated. The colour of dried arils was observed visually by comparing with colour cards of Royal Horticulture Society, London. Water activity of the dried arils was estimated by computer based digital water activity meter (HW3 model, Rotronic International, Switzerland). Total Soluble Solids (TSS) of fresh arils were measured and expressed in degree brix $\left({ }^{\circ} \mathrm{B}\right)$. The moisture and total solids of fresh as well as dried arils were determined by drying the weighed samples to a constant weight in a hot air oven at $70+1{ }^{\circ} \mathrm{C}$. The titratable acidity was expressed as per cent citric acid (AOAC, 2004) and estimated by using phenolphthalein as an indicator to give pink colour (end point). The $\mathrm{pH}$ of fresh as well as dried arils was determined by using a digital $\mathrm{pH}$ meter (CRISON Instrument, Ltd, Spain). Sugars, pectin, ash and Hydroxyl Methyl Furfural (HMF) were estimated as per the standard procedures given by Ranganna (2009). Ascorbic acid content was determined as per AOAC (2004) method using 2, 6-dichlorophenol -indophonol dye. The total phenolic content was determined by the Folic-Ciocalteu procedure (Singleton and Rossi, 1965). The total anthocyanins and Non Enzymatic Browning (NEB) of samples were determined by the standardized methods (Ranganna, 2009) by using a UV-Vis spectrophotometer (Model Shimadzu, Japan). Furfural was estimated by a colorimetric method based upon its reaction with aniline and acetic acid in the presence of acidified $\mathrm{SnCl}_{2}$ (Dinsmore and Nagy, 1974).

Statistical analysis: The data for quantitative estimation of various physico-chemical attributes were analyzed by Completely Randomized Design (CRD) while the data on sensory analysis were analyzed by Randomized Block Design (RBD).

\section{RESULTS}

Perusal of data mentioned in the Table 2 represent $55.99 \mathrm{~mm}, 43.26 \mathrm{~mm}$ and $61 \mathrm{~g}$ of average length, diameter and weight of wild pomegranate fruits, respectively. The number and weight of arils per fruit were 230 and $32.73 \mathrm{~g}$, respectively. The visual colour of mature fruit was found to be yellowish green, whereas, the colour of arils was observed as pinkish red. The average moisture content and total solids in fresh arils were $71.10 \%$ and $28.90 \%$, whereas, in dried arils $8.79 \%$ of moisture and $91.21 \%$ of total solids were recorded. Average TSS in the fruit arils were recorded as $18{ }^{\circ} \mathrm{B}$, while the reducing and total sugars in the arils were found to be $7.67 \%$ and $8.48 \%$, respectively. In mechanical cabinet dried arils, these quality parameters i.e. TSS, reducing and total sugars get increased upto the values of $41{ }^{\circ} \mathrm{B}, 20.01 \%$ and $24.32 \%$, respectively. In the fresh arils, titratable acidity and $\mathrm{pH}$ were observed as $3.87 \%$ (as \% citric acid) and 2.62, respectively, whereas, in dried arils, titratable acidity was recorded as $11.20 \%$ and $\mathrm{pH}$ as 3.70. Data pertaining to characteristics of fresh fruit arils reveal that it also contained sufficient amount of ascorbic acid (23.06 $\mathrm{mg} / 100 \mathrm{~g})$, anthocyanins $(9.73 \mathrm{mg} / 100 \mathrm{~g})$ and phenols

Table 1. Detail of treatment.

\begin{tabular}{lc}
\hline \multicolumn{1}{c}{ Treatment } & Treatment symbol \\
\hline Dried arils in ALP & $\mathrm{T}_{1}$ \\
Dried arils in PEP & $\mathrm{T}_{2}$ \\
Dried arils in TT & $\mathrm{T}_{3}$ \\
Dried arils in ALP+5\% cane sugar & $\mathrm{T}_{4}$ \\
Dried arils in PEP+5\% cane sugar & $\mathrm{T}_{5}$ \\
Dried arils in TT $+5 \%$ cane sugar & $\mathrm{T}_{6}$ \\
Dried arils in ALP $+5 \%$ common salt & $\mathrm{T}_{7}$ \\
Dried arils in PEP $+5 \%$ common salt & $\mathrm{T}_{8}$ \\
Dried arils in TT $+5 \%$ common salt & $\mathrm{T}_{9}$ \\
\hline
\end{tabular}


Table 2. Physico-chemical characteristics of fresh and mechanical cabinet dried arils of wild pomegranate fruit.

\begin{tabular}{ccc}
\hline Characteristics & Fruit and fresh arils & Cabinet dried arils \\
\hline Size of Fruit & 55.99 & - \\
a) Length (mm) & 43.26 & - \\
b) Diameter (mm) & 61.00 & RP-60A \\
Weight of fruit (g) & Yellowish green & - \\
Colour of fruit & Pinkish red & - \\
Colour of arils & 230 & 0.2278 \\
Number of arils/fruit & 32.73 & 8.79 \\
Weight of arils/fruit (g) & - & 91.21 \\
Water activity & 71.1 & 41.00 \\
Moisture (\%) & 28.9 & 20.01 \\
Total solids (\%) & 18 & 24.32 \\
TSS ( $\left.{ }^{\circ} \mathrm{B}\right)$ & 7.67 & 11.20 \\
Reducing sugars (\%) & 8.48 & 3.70 \\
Total sugars (\%) & 3.87 & 13.20 \\
Titratable acidity (\% CA* $)$ & 2.62 & 0.04 \\
pH & 23.06 & 32.89 \\
Ascorbic acid (mg/100g) & - & 116.9 \\
NEB (OD) & 9.73 & 3.18
\end{tabular}

CA*: Citric acid, RP: Red purple, 60 A: Card number of Royal Horticulture Society

(89.67 mg/100g). In mechanical cabinet dried arils, $13.20 \mathrm{mg} / 100 \mathrm{~g}, 32.89 \mathrm{mg} / 100 \mathrm{~g}$ and $116.90 \mathrm{mg} / 100 \mathrm{~g}$ of ascorbic acid, anthocyanins and phenols were recorded, respectively. The pectin and ash content of fruit were observed as $0.70 \%$ and $0.87 \%$, whereas, dried arils contained $3.18 \%$ pectin and $4.24 \%$ ash content. NEB, HMF and furfural content of dried arils were found as $0.04 \mathrm{OD}, 0.90 \mathrm{ppm}$ and $12.09 \mathrm{ppb}$, respectively.

Results in Tables 3 and 5 and Figs. 1-3 indicate that there was a general increase in water activity, moisture, reducing sugar, NEB, HMF and furfural of mechanical cabinet dried arils during storage of 6 months. Data presented in the tables 4-6 and Fig. 4 reveals that titratable acidity, ascorbic acid, total sugar, anthocyanins, phenols, colour, texture, taste and overall acceptability of dried arils generally decreased with the advancement of storage period. The water activity, moisture and reducing sugar of dried arils increased significantly from 0.2278 to $0.3007,8.79 \%$ to $9.50 \%$ and $20.01 \%$ to $20.29 \%$, respectively, during storage of 6 months. However, the titratable acidity and total sugars of dried arils decreased significantly from $11.20 \%$ to $10.43 \%$ and $24.32 \%$ to $23.83 \%$, respectively. A significant decrease in ascorbic acid, anthocyanins and phenols was also recorded from initial values of 13.20 $\mathrm{mg} / 100 \mathrm{~g}, 32.89 \mathrm{mg} / 100 \mathrm{~g}$ and $116.90 \mathrm{mg} / 100 \mathrm{~g}$ to final values of $8.19 \mathrm{mg} / 100 \mathrm{~g}, 22.85 \mathrm{mg} / 100 \mathrm{~g}$ and 101.43 $\mathrm{mg} / 100 \mathrm{~g}$, respectively. The NEB, HMF and furfurals of dried arils increased significantly from initial values of $0.04 \mathrm{OD}, 0.90 \mathrm{ppm}$ and $12.09 \mathrm{ppb}$ to $0.15 \mathrm{OD}, 5.32$ ppm and $32.98 \mathrm{ppb}$, respectively, during storage. While comparing different packaging material, maximum titratable acidity, ascorbic acid, total sugars, anthocyanins and phenols were recorded in $\mathrm{ALP}+5 \%$ salt $\left(\mathrm{T}_{7}\right)$ closely followed by $\mathrm{T}_{4}$ and $\mathrm{T}_{1}$, however, the minimum were recorded in TT $\left(\mathrm{T}_{3}\right)$ during storage of 6 months. Among the different packaging material, minimum water activity, moisture, NEB, furfural and HMF of dried arils were recorded in ALP $+5 \%$ salt $\left(\mathrm{T}_{7}\right)$ closely followed by $\mathrm{T}_{4}$ and $\mathrm{T}_{1}$ and maximum in TT $\left(\mathrm{T}_{3}\right)$ during storage. Results pertaining to changes in sensory scores (colour, texture, taste and overall acceptability) of dried arils during storage are presented in Fig. 4. The colour, texture, taste and overall acceptability scores of dried arils decreased during storage of six months. Further, when the different packaging treatments were compared, maximum scores for sensory attributes was observed in the dried arils packed in ALP $+5 \%$ salt $\left(\mathrm{T}_{7}\right)$ which was at par with $\mathrm{T}_{1}$ and $\mathrm{T}_{4}$, and minimum in TT $\left(\mathrm{T}_{3}\right)$ closely followed by $\mathrm{T}_{6}$ during storage (Fig. 4).

\section{DISCUSSION}

Fresh wild pomegranate fruit characteristics observed in the present studies are in accordance with the results reported by Thakur et al. (2010) and Thakur et al. 
Table 3. Effect of different packaging treatments on the water activity and moisture (\%) of dried wild pomegranate arils during storage.

\begin{tabular}{|c|c|c|c|c|c|c|c|c|}
\hline \multirow{3}{*}{$\begin{array}{l}\text { Treatment } \\
\text { (T) }\end{array}$} & \multicolumn{4}{|c|}{ Water activity } & \multicolumn{4}{|c|}{ Moisture (\%) } \\
\hline & \multicolumn{3}{|c|}{$\begin{array}{c}\text { Storage interval (I) } \\
\text { (Months) }\end{array}$} & \multirow[t]{2}{*}{ Mean (T) } & \multicolumn{3}{|c|}{$\begin{array}{c}\text { Storage interval (I) } \\
\text { (Months) }\end{array}$} & \multirow[t]{2}{*}{ Mean (T) } \\
\hline & 0 & 3 & 6 & & $\mathbf{0}$ & 3 & 6 & \\
\hline$\overline{\mathrm{T}_{1}}$ & 0.2278 & 0.2368 & 0.2398 & 0.2348 & 8.79 & 8.84 & 8.87 & 8.83 \\
\hline $\mathrm{T}_{2}$ & 0.2278 & 0.2701 & 0.2851 & 0.2610 & 8.79 & 9.15 & 9.22 & 9.05 \\
\hline $\mathrm{T}_{3}$ & 0.2278 & 0.3608 & 0.4002 & 0.3296 & 8.79 & 10.34 & 10.85 & 9.99 \\
\hline $\mathrm{T}_{4}$ & 0.2278 & 0.2345 & 0.2385 & 0.2336 & 8.79 & 8.83 & 8.87 & 8.83 \\
\hline $\mathrm{T}_{5}$ & 0.2278 & 0.2651 & 0.2768 & 0.2566 & 8.79 & 9.10 & 9.16 & 9.01 \\
\hline $\mathrm{T}_{6}$ & 0.2278 & 0.3469 & 0.3824 & 0.3190 & 8.79 & 9.86 & 10.35 & 9.66 \\
\hline $\mathrm{T}_{7}$ & 0.2278 & 0.2331 & 0.2365 & 0.2325 & 8.79 & 8.83 & 8.85 & 8.82 \\
\hline $\mathrm{T}_{8}$ & 0.2278 & 0.2592 & 0.2724 & 0.2531 & 8.79 & 9.05 & 9.12 & 8.98 \\
\hline $\mathrm{T}_{9}$ & 0.2278 & 0.3443 & 0.3742 & 0.3154 & 8.79 & 9.71 & 10.24 & 9.58 \\
\hline Mean (I) & 0.2278 & 0.2834 & 0.3007 & & 8.79 & 9.30 & 9.50 & \\
\hline C.D. ${ }_{(0.05)}$ & \multicolumn{4}{|c|}{$\mathrm{T}=0.0030, \mathrm{I}=0.0060, \mathrm{TxI}=0.0090$} & \multicolumn{4}{|c|}{$\mathrm{T}=0.05, \mathrm{I}=0.09, \mathrm{TxI}=0.14$} \\
\hline
\end{tabular}

Table 4. Effect of different packaging treatments on titratable acidity (\%) and ascorbic acid (mg/100g) of dried wild pomegranate arils during storage.

\begin{tabular}{|c|c|c|c|c|c|c|c|c|}
\hline \multirow[t]{3}{*}{ Treatment (T) } & \multicolumn{4}{|c|}{ Titratable acidity (\%) } & \multicolumn{4}{|c|}{ Ascorbic acid (mg/100 g) } \\
\hline & \multicolumn{3}{|c|}{$\begin{array}{l}\text { Storage interval (I) } \\
\text { (Months) }\end{array}$} & \multirow[t]{2}{*}{$\begin{array}{l}\text { Mean } \\
(T)\end{array}$} & \multicolumn{3}{|c|}{$\begin{array}{c}\text { Storage interval (I) } \\
\text { (Months) }\end{array}$} & \multirow[t]{2}{*}{$\begin{array}{l}\text { Mean } \\
\text { (T) }\end{array}$} \\
\hline & $\mathbf{0}$ & 3 & 6 & & $\mathbf{0}$ & 3 & 6 & \\
\hline $\mathrm{T}_{1}$ & 11.20 & 10.82 & 10.72 & 10.91 & 13.20 & 11.83 & 9.90 & 11.64 \\
\hline $\mathrm{T}_{2}$ & 11.20 & 10.60 & 10.42 & 10.74 & 13.20 & 10.62 & 8.10 & 10.64 \\
\hline $\mathrm{T}_{3}$ & 11.20 & 10.22 & 10.05 & 10.49 & 13.20 & 9.03 & 5.88 & 9.37 \\
\hline $\mathrm{T}_{4}$ & 11.20 & 10.85 & 10.69 & 10.91 & 13.20 & 11.88 & 10.10 & 11.72 \\
\hline $\mathrm{T}_{5}$ & 11.20 & 10.66 & 10.48 & 10.78 & 13.20 & 10.81 & 8.56 & 10.85 \\
\hline $\mathrm{T}_{6}$ & 11.20 & 10.30 & 10.12 & 10.54 & 13.20 & 9.15 & 6.12 & 9.49 \\
\hline $\mathrm{T}_{7}$ & 11.20 & 10.88 & 10.69 & 10.92 & 13.20 & 11.91 & 10.15 & 11.75 \\
\hline $\mathrm{T}_{8}$ & 11.20 & 10.70 & 10.54 & 10.81 & 13.20 & 10.89 & 8.68 & 10.92 \\
\hline $\mathrm{T}_{9}$ & 11.20 & 10.35 & 10.18 & 10.57 & 13.20 & 9.21 & 6.25 & 9.55 \\
\hline Mean (I) & 11.20 & 10.59 & 10.43 & & 13.20 & 10.59 & 8.19 & \\
\hline C.D. ${ }_{(0.05)}$ & \multicolumn{4}{|c|}{$\mathrm{T}=0.02, \mathrm{I}=0.04, \mathrm{TxI}=0.06$} & \multicolumn{4}{|c|}{$\mathrm{T}=0.13, \mathrm{I}=0.16, \mathrm{TxI}=0.28$} \\
\hline
\end{tabular}

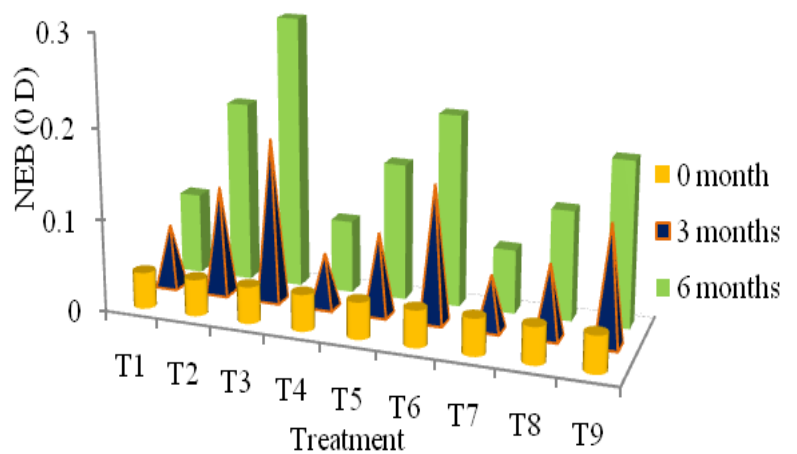

Fig. 1. Effect of different packaging treatments on non enzymatic browning $(O D)$ of dried wild pomegranate arils during storage.

(2011). Significantly higher values were recorded for different quality parameters of dried arils in comparision of the fresh arils of the same quantity. During mechanical cabinet dehydration, concentration of dissolved solids, reduction in moisture content as well

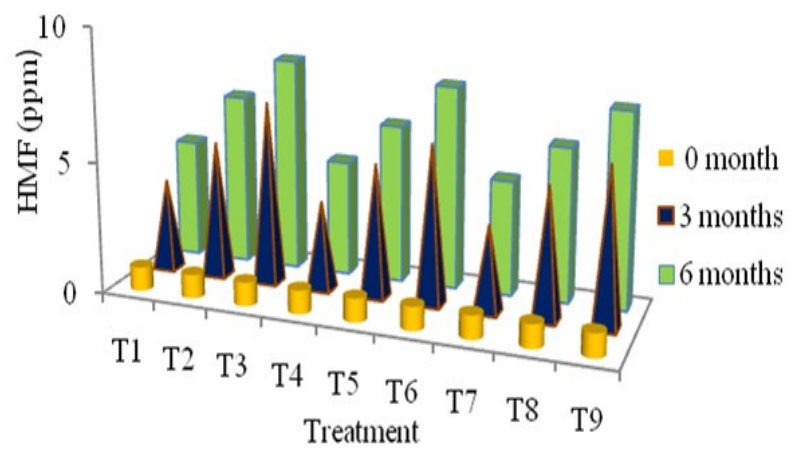

Fig. 2. Effect of different packaging treatments on hydroxy methyl furfural (ppm) of dried wild pomegranate arils during storage.

as in total bulk mass might have contributed to significant increase in the values of physico-chemical attributes of arils. Similar findings have been obtained by Singh and Kingsley (2008), Thakur et al. (2010) and Sharma et al. (2013) for quality attributes of dried 
Table 5. Effect of different packaging treatments on reducing sugar (\%) and total sugar (\%) of dried wild pomegranate arils during storage.

\begin{tabular}{|c|c|c|c|c|c|c|c|c|}
\hline \multirow[t]{3}{*}{ Treatment (T) } & \multicolumn{4}{|c|}{ Reducing sugar (\%) } & \multicolumn{4}{|c|}{ Total sugar (\%) } \\
\hline & \multicolumn{3}{|c|}{ Storage interval (I) (Months) } & \multirow[t]{2}{*}{ Mean (T) } & \multicolumn{3}{|c|}{ Storage interval (I) (Months) } & \multirow[t]{2}{*}{ Mean (T) } \\
\hline & $\mathbf{0}$ & 3 & 6 & & $\mathbf{0}$ & 3 & 6 & \\
\hline $\mathrm{T}_{1}$ & 20.01 & 20.18 & 20.28 & 20.15 & 24.32 & 24.12 & 24.06 & 24.15 \\
\hline $\mathrm{T}_{2}$ & 20.01 & 20.25 & 20.33 & 20.19 & 24.32 & 23.92 & 23.73 & 23.99 \\
\hline $\mathrm{T}_{3}$ & 20.01 & 20.32 & 20.40 & 20.24 & 24.32 & 23.81 & 23.53 & 23.88 \\
\hline $\mathrm{T}_{4}$ & 20.01 & 20.15 & 20.23 & 20.13 & 24.32 & 24.15 & 24.12 & 24.19 \\
\hline $\mathrm{T}_{5}$ & 20.01 & 20.22 & 20.31 & 20.18 & 24.32 & 24.00 & 23.82 & 24.04 \\
\hline $\mathrm{T}_{6}$ & 20.01 & 20.31 & 20.36 & 20.22 & 24.32 & 23.92 & 23.60 & 23.94 \\
\hline $\mathrm{T}_{7}$ & 20.01 & 20.11 & 20.15 & 20.09 & 24.32 & 24.16 & 24.14 & 24.20 \\
\hline $\mathrm{T}_{8}$ & 20.01 & 20.20 & 20.26 & 20.15 & 24.32 & 24.06 & 23.90 & 24.09 \\
\hline $\mathrm{T}_{9}$ & 20.01 & 20.29 & 20.30 & 20.20 & 24.32 & 23.98 & 20.68 & 23.99 \\
\hline Mean (I) & 20.01 & 20.22 & 20.29 & & 24.32 & 24.01 & 23.83 & \\
\hline C.D.(0.05) & & $0.03, \mathrm{I}=$ & $6, \mathrm{TxI}=$ & & & .03 , & $\overline{05, \quad \mathrm{Txl}}$ & 0.09 \\
\hline
\end{tabular}

Table 6. Effect of different packaging treatments on anthocyanins $(\mathrm{mg} / 100 \mathrm{~g})$ and phenols $(\mathrm{mg} / 100 \mathrm{~g})$ of dried wild pomegranate arils during storage.

\begin{tabular}{|c|c|c|c|c|c|c|c|c|}
\hline \multirow{3}{*}{$\begin{array}{c}\text { Treatment } \\
\text { (T) }\end{array}$} & \multicolumn{4}{|c|}{ Anthocyanins (mg/100g) } & \multicolumn{4}{|c|}{ Phenols (mg/100g) } \\
\hline & \multicolumn{3}{|c|}{ Storage interval (I) (Months) } & \multirow[t]{2}{*}{ Mean (T) } & \multicolumn{3}{|c|}{ Storage interval (I) (Months) } & \multirow[t]{2}{*}{ Mean (T) } \\
\hline & $\mathbf{0}$ & 3 & 6 & & $\mathbf{0}$ & 3 & 6 & \\
\hline $\mathrm{T}_{1}$ & 32.89 & 30.21 & 28.92 & 30.67 & 116.90 & 112.45 & 107.26 & 112.20 \\
\hline $\mathrm{T}_{2}$ & 32.89 & 26.82 & 21.24 & 26.98 & 116.90 & 104.56 & 100.15 & 107.20 \\
\hline $\mathrm{T}_{3}$ & 32.89 & 21.25 & 16.18 & 23.43 & 116.90 & 101.82 & 94.24 & 104.32 \\
\hline $\mathrm{T}_{4}$ & 32.89 & 30.42 & 29.01 & 30.77 & 116.90 & 112.85 & 107.32 & 112.36 \\
\hline $\mathrm{T}_{5}$ & 32.89 & 27.55 & 22.64 & 27.69 & 116.90 & 106.25 & 101.26 & 108.13 \\
\hline $\mathrm{T}_{6}$ & 32.89 & 22.54 & 17.48 & 24.3 & 116.90 & 103.62 & 96.12 & 105.34 \\
\hline $\mathrm{T}_{7}$ & 32.89 & 30.5 & 29.06 & 30.81 & 116.90 & 112.92 & 107.32 & 112.38 \\
\hline $\mathrm{T}_{8}$ & 32.89 & 28.24 & 23.24 & 28.12 & 116.90 & 108.60 & 102.15 & 109.21 \\
\hline $\mathrm{T}_{9}$ & 32.89 & 23.15 & 17.92 & 24.65 & 116.90 & 104.59 & 97.05 & 106.18 \\
\hline Mean (I) & 32.89 & 26.74 & 22.85 & & 116.90 & 107.29 & 101.43 & \\
\hline C.D. ${ }_{(0.05)}$ & \multicolumn{4}{|c|}{$\mathrm{T}=0.30, \mathrm{I}=0.50, \mathrm{TxI}=0.80$} & \multicolumn{4}{|c|}{$\mathrm{T}=0.20, \mathrm{I}=0.40, \mathrm{TxI}=0.60$} \\
\hline
\end{tabular}

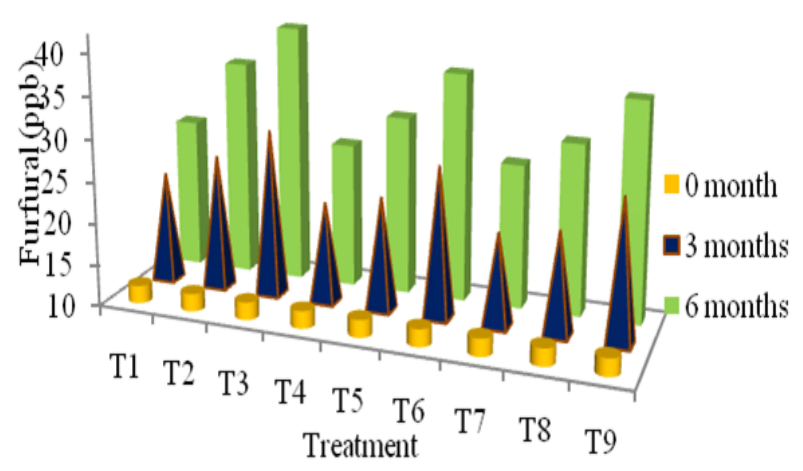

Fig. 3. Effect of different packaging treatments on furfural (ppb) of dried wild pomegranate arils during storage.

wild pomegranate arils. A general increase of water activity and moisture content observed during storage might be due to the hygroscopic nature of the dried product. Enhancement of reducing sugars of arils

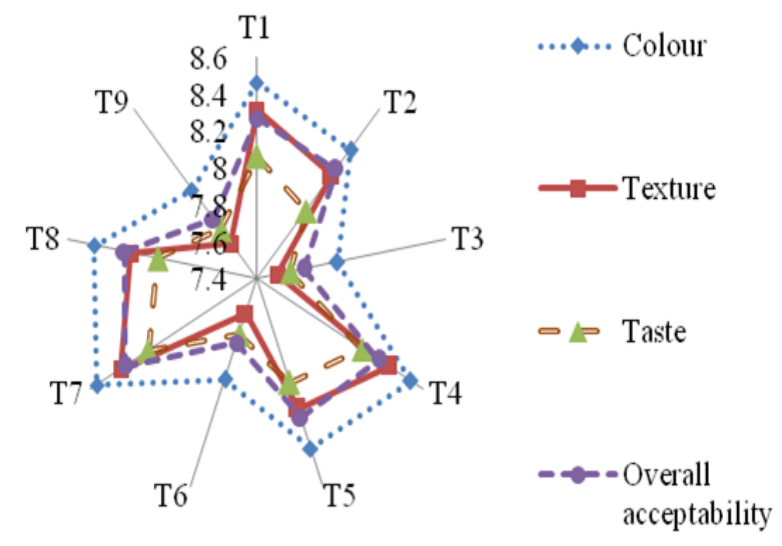

Fig. 4. Effect of different packaging treatments on sensory attributes (9 point hedonic scale scores) of dried wild pomegranate arils during storage.

during storage might be due to the inversion of non reducing sugars and other polysaccharides into reducing sugars. Utilization of acids in the inversion of non reducing sugars to reducing sugars might have 
contributed to decrease in titratable acidity. Total sugars might have decreased due to their participation in chemical reactions with amino acids for further formation of NEB and HMF products. The trend of obtained results is in agreement with the work done by Sagar and Kumar (2009) in dehydrated mango slices, Santos et al. (2012) and Sra et al. (2014) in dried carrot slices. Dried arils packed in ALP+5\% salt, ALP+5\% sugar and ALP recorded significantly minimum increase of above chemical characteristics during storage as compared to other packaging material where these were more. This might be due to the air which remained trapped inside the pouch at the time of manual sealing or it may be because of the minute permeable nature (as a result of pin holes in the aluminium foil) of ALP which might have given the way for the slight movement of moisture and air inside the pouch. Other reason for the minimum increase in the values of these characteristics by arils packed in ALP containing either salt or sugar might be due the hygroscopic property of these humectants which attracted the moisture more than arils and restriction on undesirable biochemical reactions under moist conditions. The higher increase in these quality characteristics in polyethylene pouch and thermofoam tray might be due to their higher permeability to air and moisture. Similar trend of findings have been revealed by Sharma et al. (2000) in dried apricots, Chandel (2011) in functionally enriched fruit rolls and Thakur et al. (2012) in dried chilgoza, Indian pine nuts. General decrease in titratable acidity, ascorbic acid, total sugars, anthocyanins, phenols and sensory attributes was observed during storage of dried arils might be due to the increase in the moisture and air uptake, exposure of arils to light and utilization of acids in the inversion of non-reducing sugars to reducing sugars. The reason for the decrease in scores of colour and texture might be due to the formation of brown coloured pigments during non enzymatic browning reactions, loss of anthocyanins and absorption of moisture during storage. As a result of which judges rewarded lower scores to the dried arils after storage in comparision of freshly prepared dried product. Reduction in sugars, ascorbic acid and titratable acidity of dried arils might have contributed to lower scores for flavour and overall acceptability after storage of 6 months. This trend of results is in accordance with the findings of Sagar and Kumar (2009) in dehydrated mango slices and Kumar (2013) in osmo-dried plums. It is evident that decrease in titratable acidity, ascorbic acid, total sugars, anthocyanins, phenols and sensory characteristics was significantly much less in ALP+5 $\%$ salt, ALP $+5 \%$ sugar and ALP as compared to polyethylene pouch and thermofoam tray with or without salt or sugar. This might be due to the opaqueness of aluminium foil in the ALP to light and minute permeability of the packaging material to oxygen and water vapour that prevented photo-oxidation and oxidation reactions. Salt and sugar inside the pouch might also restricted the moisture penetration into anardana because of their higher moisture absorbing properties, that is why, dried arils retained better quality as compared to the other packages. Further, better packaging conditions in ALP with or without salt or sugar might also have restricted the formation of NEB, HMF and furfural because of the slower rate of chemical reactions inside these pouches. The trend of obtained findings is in agreement with the work done by Kumar (2013) in osmo-dried plum and Swain et al. (2013) in dried sweet pepper during storage.

\section{Conclusion}

Among different packaging material active packaging of ALP with or without salt or sugar were found to be the best packaging material as compared to others on the basis of better retention of various physico-chemical and sensory characteristics viz., titratable acidity, ascorbic acid, total sugars, anthocyanins, phenols, colour, texture, taste and overall acceptability. Thus, it can be concluded from these studies that the mechanical cabinet dried arils can be packed in ALP successfully and can be stored under ambient storage conditions. Active packaging of dried arils (anardana) along with salt or sugar as moisture absorbers will be an additional advantage for retaining the best quality of anardana (Indian spice).

\section{ACKNOWLEDGEMENTS}

Authors convey heartfelt thanks to the department of Food Science and Technology, UHF, Nauni, Solan for co-operation and providing the facilities to carry out this research. Authors are also grateful to farmers of Mandi district (HP) for providing wild pomegranate fruits as a main raw material for present research.

\section{REFERENCES}

AOAC (2004). Official Methods of Analysis of the Association of Official Analytical Chemists. $20^{\text {th }}$ edn. Association of Official Analytical Chemists, Washington D.C.

Bakshi, P., Bhushan, B., Wali, V.K., Bakshi, M., Sharma, A. and Bhat, D.J. (2013). Standardization of drying method and organoleptic evaluation of wild pomegranate (anardana) seeds. World Journal of Agricultural Sciences, 9(5): 397-400.

Chandel, V. (2011). Studies on functionally enriched fruit rolls. M.Sc. Thesis, Dr. Y.S. Parmar U.H.F., Nauni, Solan, H.P., India.

Dinsmore, H.L. and Nagy, S. (1974). Improved colorimetric determination of furfural in citrus juices. Journal of Association of Official Analytical Chemists, 57: 332335.

FAO. (2000). Production Year Book. Food and Agriculture Organization, Rome, pp. 54.

Jalikop, S.H., Tiwari, R.B. and Kumar, S. (2002). Amlidana: a new pomegranate hybrid. Indian Horticulture. 21(3): 22-23.

Kumar, N. (2013). Optimization of methods for the preparation of osmo dried plum (Prunus domestica). M.Sc. Thesis, 
Dr. Y.S. Parmar U.H.F., Nauni, Solan, H.P., India.

Lopez-Rubio, A., Almenar, E., Hernandez-Munoz, P., Lagaron, J.M.R., Catala and Gavara, R. (2004). Overview of active polymer-based packaging technologies for food applications. Food Review International, 20(4): 357387.

Mahajan, B.V.C., Chopra, S.K. and Sharma, R.C. (2004). Processing of wild pomegranate (Punica granatum L) for anardana: Effect of thermal treatments and drying modes on quality. Journal of Food Science and Technology, 29(5): 327-328.

Parashar, A., Gupta, S.K. and Kumar, A. (2009). Studies on separation techniques of pomegranate seeds and their effect on quality of anardana. African Journal of Biochemistry Research, 3(10): 340-343.

Pruthi, J.S. and Saxena, A.K. (2005). Studies on anardana (dried pomegranate seeds). Journal of Food Science and Technology, 21(5): 296.

Ranganna, S. (2009). Handbook of analysis and quality control for fruit and vegetable products. Tata McGraw Hill, New Delhi, p1112.

Sagar, V.R. and Kumar, P.S. (2009). Involvement of some process variables in mass transfer kinetics of osmotic dehydration of mango slices and storage stability. Journal of Scientific and Industrial Research, 68: 10431048.

Santos, J.G., Soria, A.C., Martinez, M.C., Villamiel, M. and Montilla, A. (2012). Effect of storage on quality of industrially dehydrated onion, garlic, potato and carrot. Journal of Food and Nutrition Research, 51(3): 132144.

Sharma, K.D., Kumar, R. and Lal Kaushal, B.B. (2000). Effect of packaging on quality and shelf life of osmo air dried apricots. Journal of Scientific and Industrial
Research, 59: 949-954.

Sharma, S.R., Bhatia, S., Arora, S., Mittal, T.C. and Gupta, S.K. (2013). Effect of storage conditions and packaging material on quality of anardana. International Journal of Advances in Engineering and Technology, 6(5): 2179 -2186 .

Singh, D.B. and Kinglsley, A.R.P. (2008). Effect of convective drying on quality of anardana. Indian Journal of Horticulture, 65(4): 413-416.

Singleton, V.L. and Rossi, J.A. (1965). Colorimetry of total phenolics with phosphomolybedic phosphotungstic acid reagents. American Journal of Enology and Viticulture, 16: 144-158.

Sra, S.K., Sandhu, K.S. and Ahluwalia, P. (2014). Effect of treatments and packaging on the quality of dried carrot slices during storage. Journal of Food Science and Technology, 51(4): 645-654.

Swain, S., Samuel, D.V.K. and Kar, A. (2013). Effect of packaging materials on quality characteristics of osmotically pretreated microwave assisted dried sweet pepper (Capsicum annum L.). Journal of Food Processing and Technology, 4 (9):1-7.

Thakur, N.S., Bhat, M.M., Rana, N. and Joshi, V.K. (2010). Standardization of pre-treatments for the preparation of dried arils from wild pomegranate. Journal of Food Science and Technology, 47(6): 620-625.

Thakur, N.S., Dhaygude, G.S. and Gupta, A. (2011). Physico -chemical characteristics of wild pomegranate fruits in different location of Himachal Pradesh. International Journal of Farm Science, 1(2): 37-44.

Thakur, N.S., Sharma, S., Joshi, V.K., Thakur, K.S. and Jindal, N. (2012). Studies on drying, packaging and storage of solar tunnel dried chilgoza nuts. Scholars Research Library, 4(3): 1311-1319. 